\title{
Rapid recovery of vision following early intervention with fractionated stereotactic radiotherapy for optic nerve sheath meningioma
}

This article was published in the following Dove Press journal: International Medical Case Reports Journal

\author{
Toshihiko Inoue' \\ Yoshishige Okuno' \\ Iku Nishiguchi' \\ Koji Ikenaga' \\ Osamu Mimura² \\ 'Department of Radiation Oncology, \\ Ashiya Radiotherapy Clinic Nozomi, \\ Ashiya, Japan; ${ }^{2}$ Department of Neuro- \\ Ophthalmological Therapeutics, Hyogo \\ College of Medicine, Nishinomiya, \\ Japan
}

Purpose: To report the outcomes of early intervention with fractionated stereotactic radiotherapy (FSRT) in a patient with primary optic nerve sheath meningioma (ONSM).

Patient and methods: A male patient in his early 40s underwent 5-beam FSRT at a prescribed dose of $50 \mathrm{~Gy}$ in 25 fractions over 35 days. The patient had an 11-month history of progressive visual impairment at the time of FSRT.

Results: On day 14 of treatment, the patient reported early improvement in his vision. Two weeks after the completion of FSRT, his left eye visual acuity and field recovered completely. However, the tumor regressed only slightly in the 2 years of follow-up.

Conclusion: Early intervention with FSRT for optic nerve sheath meningioma resulted in a rapid response and complete improvement of visual impairment.

Keywords: fractionated stereotactic radiotherapy, optic nerve sheath meningioma, early intervention, rapid recovery of visual impairment

\section{Plain language summary}

Why was the study done? Although there has been a substantial shift in the treatment paradigm for ONSM from surgery to FSRT, treatment with FSRT is rare in Japan.

What did the researchers do? The authors report the outcome of early intervention with FSRT in a patient with primary ONSM. They found a rapid and complete improvement of the visual impairment within 1 month of treatment. Small changes in the normal tissues and the tumor geometry could have a major effect on nerve function. Even a tumor appearing stable in neuroimages may have a major decompression, which can result in a rapid improvement of visual impairment. We believe that this early intervention should be the mainstay of therapy for ONSM in Japan.

\section{Introduction}

Orbital tumors are recognized as rare cancers and have an annual incidence rate of $<6$ per 100,000 persons in the European Union; ${ }^{1}$ therefore, optic nerve sheath meningiomas (ONSMs) are rare. During the last 2 decades, there has been a substantial shift in the treatment of ONSM from surgery to fractionated stereotactic radiotherapy (FSRT) ${ }^{2-5}$ This case report describes early intervention with FSRT in a patient with ONSM that resulted in a rapid and complete improvement of visual impairment.

\section{Patient and methods}

The patient was a man in his early 40s with an 11-month history of left subacute progressive visual impairment (left vision $[\mathrm{LV}]=0.9$ at the onset). The ophthalmologist first contacted diagnosed this condition as Leber hereditary optic atrophy because of 
the progressive visual loss with a central scotoma. The patient was referred to the Department of Ophthalmology, Hyogo College of Medicine, Japan. His visual acuity (VA) was as follows: right vision $(\mathrm{RV})=0.06(1.0 \times \mathrm{S}-6.75 \mathrm{D}: \mathrm{C}-0.75 \mathrm{D} \mathrm{Ax}$ $\left.90^{\circ}\right)$, and $L V=0.02(0.02 \times \mathrm{S}-5.00 \mathrm{D}$ : C-0.75D Ax 90 $) . \mathrm{He}$ underwent ophthalmic examinations, including funduscopy (Figure 1) and optical coherence tomography (OCT), which revealed that the total thickness of the left circumpapillary retinal nerve fiber layer (cpRNFL) was slightly thinner than its right counterpart (94\% vs 106\%). Goldmann kinetic perimetry revealed left centrocecal scotoma (Figure 2A). Because of the decreased light reflex and absence of a family history of similar presentation, an ophthalmologist (OM) suspected that an intraocular lesion was compressing the left optic nerve (ON). MRI showed a globular tumor ${ }^{6}$ measuring $7 \times 6 \mathrm{~mm}$ located on the left distal $\mathrm{ON}$ at the precanalicular portion (Figure 3 ). The patient was consequently diagnosed with ONSM and admitted to our radiotherapy clinic.

We used a 6-MV X-ray Novalis Tx ${ }^{\mathrm{TM}}$ (BrainLAB AG, Munich, Germany). A BrightSpeed ${ }^{\mathrm{Tm}}$ (GE, Boston, MA, USA) unit serving as a $\mathrm{CT}$ simulator, Brivo ${ }^{\mathrm{TM}} \mathrm{MR} 355$ 1.5T (GE) as an MRI simulator, and ECLIPSE ${ }^{\mathrm{TM}}$ Ver.10.0.42 (Varian Medical Systems, Inc., Palo Alto, CA, USA) were used in the treatment planning system. The Type- $\mathrm{S}^{\mathrm{TM}}$ thermoplastic positioning system (CIVCO, Orange City, IA, USA) was used to immobilize the patient's head, and the ExacTrac ${ }^{\mathrm{TM}} \mathrm{X}$-ray $6 \mathrm{D}$ positioning system and robotic couch (BrainLAB AG) were used in the image-guided radiotherapy system. The patient underwent 5-beam FSRT with a prescribed dose of $50 \mathrm{~Gy}$ in 25 fractions over 35 days in May 2015 (Figure 4). We defined a gross tumor volume (GTV) of $0.3 \mathrm{~cm}^{3}$ using CT and MRI,

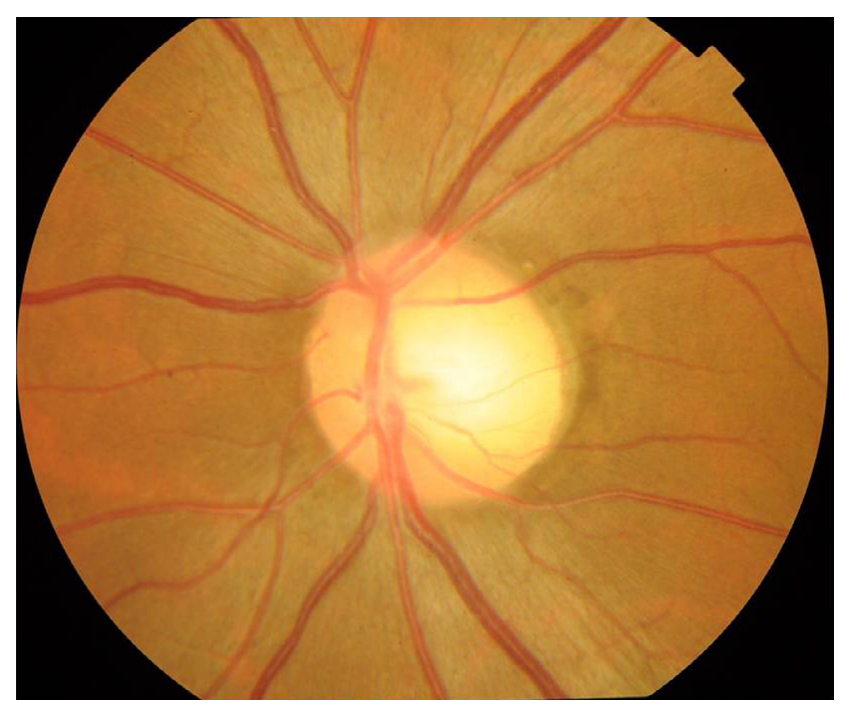

Figure I Funduscopy showed the temporal disc pallor in the left eye. and the planning target volume (PTV) was $1.7 \mathrm{~cm}^{3}$, which was based on a 3-mm margin added to the internal target volume. The maximal dose $\left(\mathrm{D}_{\max }\right)$, a dose-volume-histogram parameter, was 5591 cGy for the GTV, 5620 cGy for the PTV, 25-26 cGy for the lens, 359-266 cGy for the retinae, 2612 cGy for the right $\mathrm{ON}$, and $1478 \mathrm{cGy}$ for the pituitary gland (Table 1). We obtained written informed consent from the patient for publication of the case details and any accompanying images. The plenary meeting of this clinic approved the study design, which included a chart review.

\section{Results}

On day 14 of treatment, the patient reported an early improvement in vision. Two weeks after the completion of FSRT, his left VA had improved to the following values: $\mathrm{RV}=(1.5 \times \mathrm{S}-7.00 \mathrm{D})$, and $\mathrm{LV}=(0.8 \times \mathrm{S}-5.00 \mathrm{D}: \mathrm{C}-1.00 \mathrm{D} \mathrm{Ax}$ $\left.90^{\circ}\right)$. The centrocecal scotoma had completely disappeared (Figure 2B). However, OCT showed no change in the total thickness of the left cpRNFL (94\%). Three months later, his left VA recovered completely with the following values: $\mathrm{RV}=(1.2 \times \mathrm{S}-7.50 \mathrm{D})$, and $\mathrm{LV}=(1.5 \times \mathrm{S}-5.00 \mathrm{D}: \mathrm{C}-1.00 \mathrm{D} \mathrm{Ax}$ $90^{\circ}$ ). One year after FSRT, MRI revealed that the tumor had decreased in size to $5.0 \times 3.2 \mathrm{~mm}$. The upward shift in the left $\mathrm{ON}$ also decreased significantly (Figure 5). He has since returned to his normal life.

\section{Discussion}

ONSMs arise from the area between the arachnoid and the dural sheaths of the ON. The main blood supply to the intraocular portions of the $\mathrm{ON}$ is from the ophthalmic artery via the pia mater. ${ }^{2}$ ONSMs compromise $\mathrm{ON}$ functions by compressing the pial vascular supply, which induces ischemic changes and interferes with axonal transport in the ON. Because it is highly challenging to preserve visual function after tumor excision, surgeons experience difficulty in deciding whether or not a tumor has resulted in severe visual loss. ${ }^{7}$

In the past, the incidence of ONSM was extremely low; however, advances in neuroimaging have increased the diagnosis rate of ONSM. There are 3 patterns of ONS enlargement: tubular pattern in $64 \%$ cases, fusiform in $10 \%$, and excrescent or globular in $25 \% .{ }^{6}$ The present patient had a globular tumor on the distal $\mathrm{ON}$ at the orbital apex. In this rather rare case, the patient developed $\mathrm{ON}$ compression from the small lesion at the precanalicular portion.

FSRT was recently reported to effectively improve or stabilize the remaining visual function. VA improved in $75 \%$ of the ONSM cases, remained stable in $8 \%$, and declined in $17 \% .{ }^{3}$ A multi-institutional experience with FSRT in 23 

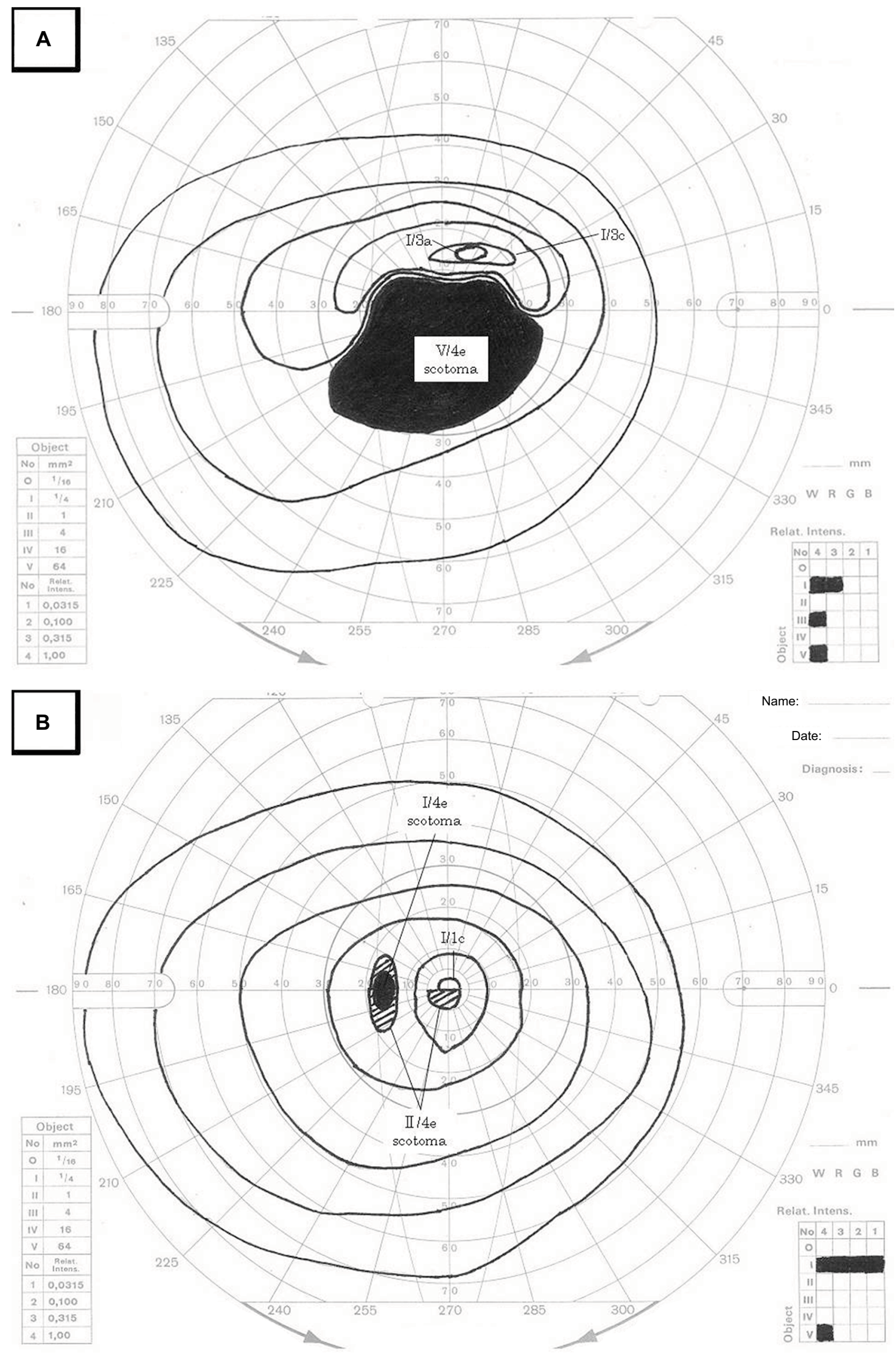

Figure 2 Rapid improvement of visual field defect.

Notes: Visual field test revealed left centrocecal scotoma, which resulted in the suspected diagnosis of left compression optic neuropathy (A). Two weeks following fractionated stereotactic radiotherapy, the visual field test improved and the centrocecal scotoma completely disappeared (B). 

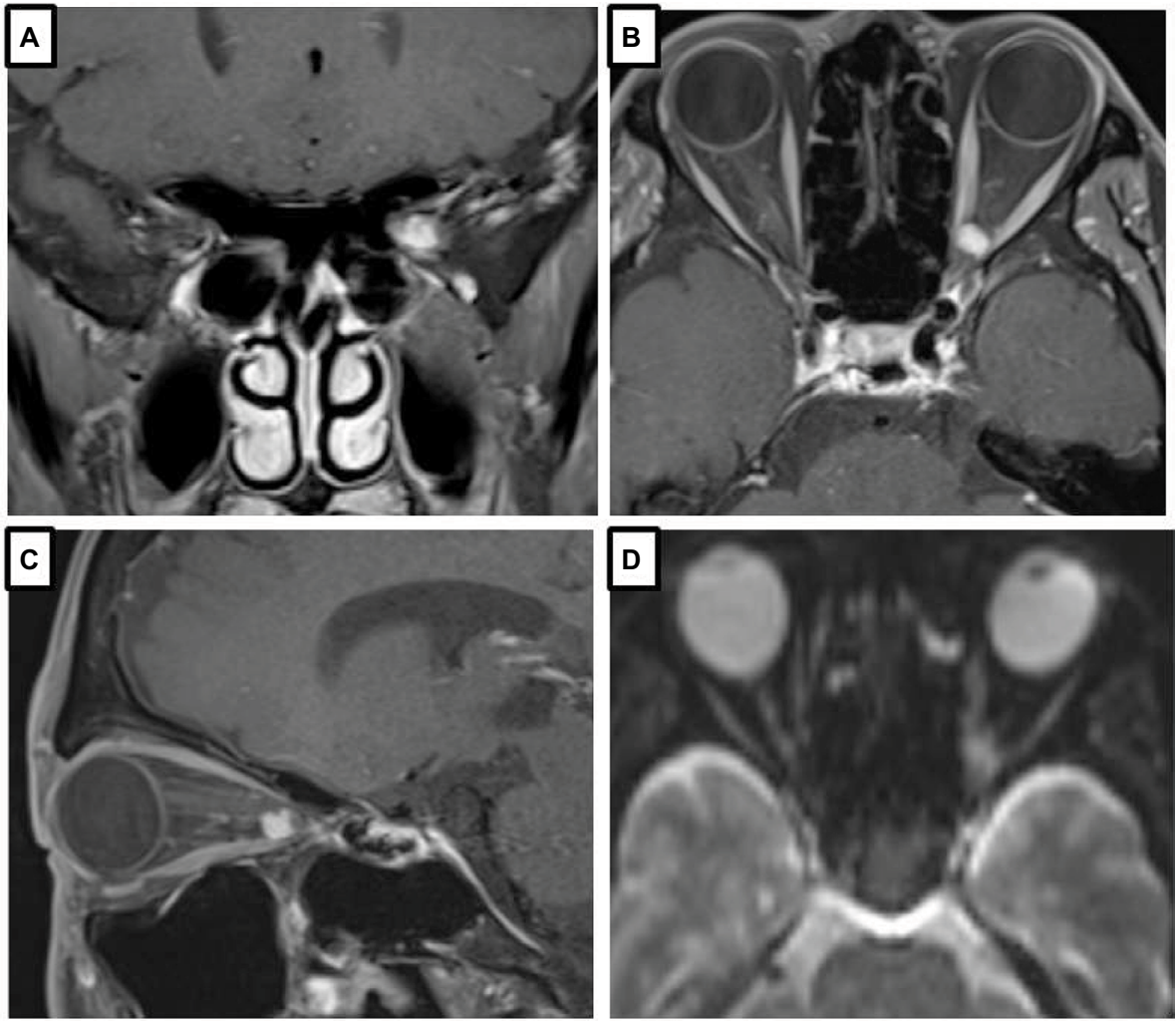

Figure 3 MRI images of a globular tumor of ONSM.

Notes: Coronal enhanced fat-suppression TIWI showed a globular tumour of ONSM on the undersurface of the left optic nerve (A). Axial enhanced fat-suppression TIWI showed homogeneous hyperintense lesion at the precanalicular portion of the left optic nerve (B). On sagittal enhanced fat-suppression TIWI, the lesion demonstrated homogeneous hyperintensity. The optic nerve was slightly compressed and slight dilatation of the perineural space was seen (C). On diffusion-weighted image, the lesion demonstrated slight heterogeneous hyperintensity (D).

Abbreviation: ONSM, optic nerve sheath meningioma; TIWI, TI-weighted image.
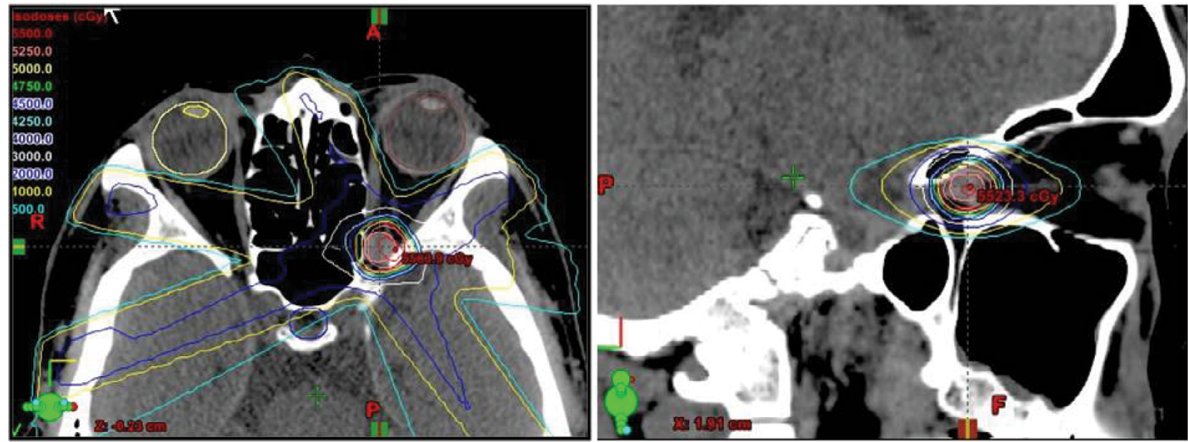

Figure 4 On treatment planning for fractionated stereotactic radiotherapy, a GTV of $0.3 \mathrm{~cm}^{3}$ was determined by CT and MRI.

Notes: The PTV was $1.7 \mathrm{~cm}^{3}$, which was decided based on a 3-mm margin added to the ITV. The prescribed dose of $50 \mathrm{~Gy}$ in 25 fractions over 35 days was delivered.

Abbreviations: GTV, gross tumor volume; ITV, internal target volume; PTV, planning target volume.

patients with primary ONSM showed that vision improved in $73 \%$ cases, remained stable in $22 \%$, and was continuously lost in 1 patient. Visual improvement was documented in 13 patients after 1-3 months of FSRT. Three patients reported subjective visual improvement during FSRT, and it was documented by ophthalmologic examination 3 months after FSRT. While visual fields improved in 8 patients, 11 showed no change. VA and visual field improvements were documented in 7 patients. ${ }^{8}$ The recommended doses of FSRT range from 43.4-45 Gy to 50-55 Gy. ${ }^{9}$ ONSMs with stable or better VA after radiotherapy were observed in patients in whom FSRT was started earlier. ${ }^{10}$

The prescribed dose for intensity-modulated radiotherapy (IMRT) was $54 \mathrm{~Gy}$, administered in 30 fractions over 6 weeks to the PTV. The dose constraints were as follows: $<8-10$ Gy for the lens, $<45$ Gy for the ipsilateral and contralateral 
retinae, $<30 \mathrm{~Gy}$ for the lacrimal gland, $<30 \mathrm{~Gy}$ for the ocular surface, $<50$ Gy for the contralateral $\mathrm{ON}$, and $<50$ Gy for the optic chiasma. ${ }^{11}$ Doses of 50-55 Gy in normofractionated regimens showed safety even after long-term follow-up. ${ }^{12}$ In general, the mean eye dose was considered as a limiting constraint, ${ }^{13}$ and was related to the tumor size and location. ${ }^{10}$

Among 25 patients irradiated with proton, 95\% had improved or stable visual function and $12 \%$ developed asymptomatic retinopathy. ${ }^{14}$ Saeed et al reported an overall visual control of $91 \%$ and 2 cases of retinopathy. ${ }^{15}$ According to Pacelli et al's report, symptoms improved in all patients; however, MRI showed that tumor sizes remained the same when compared with the pre-treatment images. ${ }^{16}$

Because the conventional tolerance dose proposed for the retina and $\mathrm{ON}$ in conventional fractionated radiotherapy does not apply to the modern precision radiotherapy, ${ }^{17,18}$ updated information is necessary to determine the relevant tolerance dose for future IMRT and particle beam treatment strategies. In addition, large clinical trials are needed to clarify

Table I DVH parameters for FSRT using Novalis 6 MV X-ray

\begin{tabular}{lllll}
\hline Structure & $\begin{array}{l}\text { Volume } \\
\left(\mathbf{c m}^{3}\right)\end{array}$ & $\mathbf{D}_{\min }(\mathbf{c G y})$ & $\mathbf{D}_{\max }(\mathbf{c G y})$ & $\mathbf{D}_{\text {mean }}(\mathbf{c G y})$ \\
\hline GTV & 0.3 & 5093.2 & 5591.1 & 5421.9 \\
PTV & 1.7 & 4391.6 & 5620.3 & 5211.8 \\
R eye & 8.5 & 9.6 & 327.5 & 29.1 \\
L eye & 7.9 & 19.7 & 284.1 & 42.1 \\
R lens & 0.1 & 12.2 & 25.1 & 17.2 \\
L lens & 0.1 & 22.1 & 26.3 & 24.3 \\
R retina & 1.1 & 12.4 & 358.6 & 57.5 \\
L retina & 1.1 & 24.5 & 265.6 & 72.5 \\
R optic nerve & 0.7 & 88.9 & 2261.5 & 1322.6 \\
Pituitary & 0.6 & 65.3 & 1478.1 & 560.3 \\
\hline
\end{tabular}

Abbreviations: $D_{\text {max }}$, maximal dose; $D_{\text {mean }}$, mean dose; $D_{\text {min }}$, minimal dose; $D V H$, dose-volume-histogram; FSRT, fractionated stereotactic radiotherapy; GTV, gross tumor volume; L, left; PTV, planning target volume; R, right. the effectiveness of IMRT over 3-dimensional conformal radiotherapy in head and neck lesions. ${ }^{19}$ Zenda et al reported that, all 4 patients, who developed $\mathrm{ON}$ disorders had received a proton dose of $53.2 \mathrm{GyE}$ in 15 fractions to $65.3 \mathrm{GyE}$ in 26 fractions for head and neck malignancies. ${ }^{20}$ In a study of carbon-beam radiotherapy, 11 of the 19 patients whose ONs were irradiated with $>57$ GyE $\left(\mathrm{D}_{\max }\right)$ developed radiation optic neuropathy. In addition, a dose of $20 \%$ of the volume of the ON $\left(\mathrm{D}_{20}\right)$ was significantly associated with visual loss. ${ }^{21}$ Therefore, the accumulation of precise treatment data for precision radiotherapy for ONSM is currently necessary.

Because the $\mathrm{D}_{\max }$ in this case was 358 and $265 \mathrm{cGy}$ for the right and left retinae, respectively, the patient only has a slight risk of radiation retinopathy. He has a $5 \%$ risk of radiation optic neuropathy because the $\mathrm{D}_{\max }$ was 5591 and 5620 cGy for the left GTV and PTV, respectively. ${ }^{9}$ Although he has not yet experienced any adverse events, the final evaluation should be performed after some more time to assess for any benign diseases.

The total thickness of the cpRNFL did not change 2 weeks after completion of FSRT in this case. However, even small changes in the normal tissue and tumor geometry could have a major impact on nerve function. Therefore, a tumor appearing stable on neuroimaging may experience a major decompression, resulting in a rapid improvement of visual impairment.

\section{Conclusion}

There has been a substantial shift in the treatment paradigm for ONSM from surgery to FSRT. We found that early intervention for ONSM resulted in a rapid and complete recovery of the vision within 1 month of treatment. Although decades of follow-up are needed because of the benign nature of the
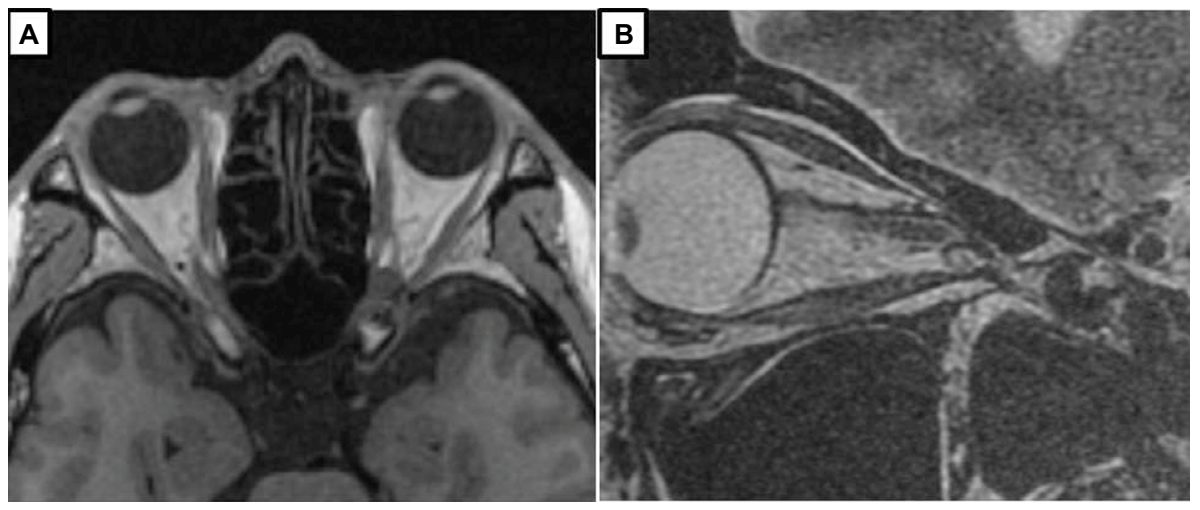

Figure 5 MRI images after FSRT for ONSM.

Notes: One year after fractionated stereotactic radiotherapy, coronal TI-weighted image showed a small decrease in the size of the hypointense lesion of $5.0 \times 3.2 \mathrm{~mm}(\mathbf{A})$. On sagittal T2-weighted image, the upward shift of the left optic nerve significantly decreased (B). 
disease, we are convinced that this early intervention with FSRT may be the mainstay of therapy for ONSM.

\section{Acknowledgments}

The authors thank Atuyuki Ohashi for preparing the neuroimaging and dosimetric data of the FSRT. We would like to thank Editage (www.editage.jp) for English language editing.

\section{Disclosure}

The authors report no conflicts of interest in this work.

\section{References}

1. Tamaki T, Dong Y, Ohno Y, Sobue T, Nishimoto H, Shibata A. The burden of rare cancer in Japan: application of the RARECARE definition. Cancer Epidemiol. 2014;38(5):490-495.

2. Jeremić B, Wasik MW, Villà $\mathrm{S}$, et al. Stereotactic radiation therapy in primary optic nerve sheath meningioma. In: Jeremić B, Pitz S, editors. Primary Optic Nerve Sheath Meningioma. Berlin Heidelberg: SpringerVerlag; 2008:105-127.

3. Dutton JJ. Optic nerve sheath meningiomas. Surv Ophthalmol. 1992;37(3):167-183.

4. Pitz S, Becker G, Schiefer U, et al. Stereotactic fractionated irradiation of optic nerve sheath meningioma: a new treatment alternative. $\mathrm{Br} J$ Ophthalmol. 2002;86(11):1265-1268.

5. Eddleman CS, Liu JK. Optic nerve sheath meningioma: current diagnosis and treatment. Neurosurg Focus. 2007;23(5):E4.

6. Ortiz O, Schochet SS, Kotzan JM, Kotstick D. Radiologic-pathologic correlation meningioma of the optic nerve sheath. AJNR Am J Neuroradiol. 1996;17(5):901-906.

7. McLean IW, Burnier MN, Zimmerman LE, Jakobiec FA. Tumors of the optic nerve and optic nerve head. In: Rosai J and Sobin LH, editors. Tumors of the Eye and Ocular Adnexa, Atlas of Tumor Pathology, Third Series Fascicle 12, Washington D.C, USA: Armed Forces Institute of Pathology; 1994:209-316.

8. Baumert BG, Villà $\mathrm{S}$, Studer $\mathrm{G}$, et al. Early improvements in vision after fractionated stereotactic radiotherapy for primary optic nerve sheath meningioma. Radiother Oncol. 2004;72(2):169-174.
9. Jeremic B, Pitz S. Primary optic nerve sheath meningioma, Stereotactic fractionated radiation therapy as an emerging treatment of choice. Cancer. 2007;110(4):714-722.

10. Adams G, Roos DE, Crompton JL. Radiotherapy for optic nerve sheath meningioma: a case for earlier intervention? Clin Oncol (R Coll Radiol). 2013;25(6):356-361.

11. Boyer AL, Butler EB, DiPetrillo TA, et al; IMRT Collaborative Working Group. Intensity-modulated radiotherapy: current status and issues of interest. Int J Radiat Oncol Biol Phys. 2001;51(4):880-914.

12. Adeberg S, Welzel T, Rieken S, Debus J, Combs SE. Prior surgical intervention and tumor size impact clinical outcome after precision radiotherapy for the treatment of optic nerve sheath meningiomas (ONSM). Radiat Oncol. 2011;6:117.

13. Abouaf L, Girard N, Lefort T, et al. Standard-fractionated radiotherapy for optic nerve sheath meningioma: visual outcome is predicted by mean eye dose. Int J Radiat Oncol Biol Phys. 2012;82(3):1268-1277.

14. Arvold ND, Lessell S, Bussiere M, et al. Visual outcome and tumor control after conformal radiotherapy for patients with optic nerve sheath meningioma. Int J Radiat Oncol Biol Phys. 2009;75(4):1166-1172.

15. Saeed P, Blank L, Selva D, et al. Primary radiotherapy in progressive optic nerve sheath meningiomas: a long-term follow-up study. $\mathrm{Br} J$ Ophthalmol. 2010;94(5):564-568.

16. Pacelli R, Cella L, Conson M, et al. Fractionated stereotactic radiation therapy for orbital optic nerve sheath meningioma - a single institution experience and a short review of the literature. J Radiat Res. 2011;52(1): $82-87$.

17. Emami B, Lyman J, Brown A, et al. Tolerance of normal tissue to therapeutic irradiation. Int J Radiat Oncol Biol Phys. 1991;21(1):109-122.

18. Marks LB, Yorke ED, Jackson A, et al. Use of normal tissue complication probability models in the clinic. Int J Radiat Oncol Biol Phys. 2010;76(3 Suppl):S10-S19.

19. Nakamura K, Sasaki T, Ohga S, et al. Recent advances in radiation oncology: intensity-modulated radiotherapy, a clinical perspective. Int J Clin Oncol. 2014;19(4):564-569.

20. Zenda S, Kawashima M, Arahira S, et al. Late toxicity of proton beam therapy for patients with the nasal cavity, para-nasal sinuses, or involving the skull base malignancy: importance of long-term follow-up. Int J Clin Oncol. 2015;20(3):447-454.

21. Hasegawa A, Mizoe JE, Mizota A, Tsujii H. Outcomes of visual acuity in carbon ion radiotherapy: analysis of dose-volume histograms and prognostic factors. Int J Radiat Oncol Biol Phys. 2006;64(2):396-401.
International Medical Case Reports Journal

\section{Publish your work in this journal}

The International Medical Case Reports Journal is an international, peer-reviewed open-access journal publishing original case reports from all medical specialties. Previously unpublished medical posters are also accepted relating to any area of clinical or preclinical science. Submissions should not normally exceed 2,000 words or

\section{Dovepress}

4 published pages including figures, diagrams and references. The manuscript management system is completely online and includes a very quick and fair peer-review system, which is all easy to use. Visit $\mathrm{http}: / /$ www.dovepress.com/testimonials.php to read real quotes from published authors. 